\title{
Lipopolysaccharide-QD Micelles Induce Marked Induction of TLR2 and Lipid Droplet Accumulation in Olfactory Bulb Microglia
}

\author{
Mélanie Lalancette-Hébert, ${ }^{\dagger, \$}$ Alexandre Moquin, ${ }^{\ddagger, \S}$ Angela O. Choi," \\ Jasna Kriz, ${ }^{* \dagger}$ and Dusica Maysinger ${ }^{*}, \|$ \\ Department of Psychiatry and Neuroscience, Centre de Recherche du CHUL, Faculty of \\ Medicine, Laval University, Quebec, QC, Canada, Faculty of Pharmacy and Department of \\ Chemistry, Université de Montreal, Montreal, QC, Canada, and Department of \\ Pharmacology and Therapeutics, Faculty of Medicine, McGill University, \\ Montreal, QC, Canada
}

Received February 16, 2010; Revised Manuscript Received May 4, 2010; Accepted May 11, 2010

\begin{abstract}
The intranasal entry of biological and artificial nanoparticles can induce inflammatory responses both locally and more widely in surrounding tissues. The aim of this study was to assess the microglia activation induced by nanoparticles with different surfaces in (i) a transgenic mouse (Toll-like receptor (TLR)-2-luciferase (Luc) reporter) which allowed the biophotonic imaging of microglial activation/innate immune response after intranasal delivery of nanoparticles and (ii) in microglial dispersed cells in vitro. Cadmium selenide nanoparticles (quantum dots, QD), surfaceexchanged with lipopolysaccharide (LPS) to form micelles, were tested to assess microglia activation and lipid droplet formation in both model systems. In vivo imaging revealed a robust increase in the extent of microglial activation/TLR2 response, initially in the olfactory bulb, but also in other more caudal brain regions. The increased TLR2 expression was complemented with enhanced CD68 expression in activated microglia in the same regions. Intense in vitro microglial activation by LPSQD micelles was accompanied by a significant enhancement of nitric oxide production and formation of large lipid droplets, suggesting the possibility of this organelle acting as an inflammatory biomarker in response to nanoparticles, and not simply as a storage site in fat tissues.
\end{abstract}

Keywords: Nanomaterials; intranasal delivery; microglia; quantum dots; lipid droplet; lipopolysaccharides; biophotonic imaging; transgenic-reporter mice

\section{Introduction}

Intranasal administration provides a noninvasive route of drug and nanoparticle entry to the brain bypassing the blood

\footnotetext{
* Corresponding authors. Dusica Maysinger, PhD, Department of Pharmacology \& Therapeutics, McGill University, 3655 Promenade Sir-William-Osler, McIntyre Medical Sciences Building, Room 1314, Montreal, QC, H3G 1Y6, Canada; tel, 514-398-1264; fax, 514-398-6690; e-mail, dusica.maysinger@ mcgill.ca. Jasna Kriz, MD, PhD, Department of Psychiatry and Neuroscience, Faculty of Medicine, Centre de Recherche du CHUL (CHUQ), T3-67, Université Laval, 2705 boulevard Laurier, Québec (QC), G1 V 4G2, Canada; tel, 418-6542296 \# 46308; fax, 418-654-2761; E-mail: jasna.kriz@ crchul.ulaval.ca.

$\dagger$ Laval University.

$¥$ These authors contributed equally to the study.
}

brain barrier. Artificial nanoparticles, both pristine and those contaminated with bacterial toxins, can enter the central nervous system (CNS) via this route. Intranasally administered compounds can reach the brain via olfactory and/or trigeminal neuronal pathways. ${ }^{1-3}$ Several studies show the effects of intransally delivered growth factors, ${ }^{4,5}$ lipopolysaccharide (LPS), ${ }^{6}$ vaccines and proteins. ${ }^{7}$ LPS, a product of

\footnotetext{
$\S$ Université de Montreal.

"McGill University.

(1) Mathison, S.; Nagilla, R.; Kompella, U. B. Nasal route for direct delivery of solutes to the central nervous system: fact or fiction. J. Drug Targeting 1998, 5 (6), 415-41.

(2) Hanson, L. R.; Frey, W. H. 2nd, Intranasal delivery bypasses the blood-brain barrier to target therapeutic agents to the central nervous system and treat neurodegenerative disease. $\mathrm{BMC} \mathrm{Neu-}$ rosci. 2008, 9 (3), S5.
}

VOL. 7, NO. 4, 1183-1194 MOLECULAR PHARMACEUTICS 1183 
Gram-negative bacteria commonly used to induce a transient inflammation in animals and in cells in cultures, can stimulate activation and migration of microglia in the olfactory bulb. ${ }^{6}$ The innate immune response may serve as an important modifier of therapeutic and/or toxic effects in the brain; thus there is a need to develop valid markers and models to assess immune responses to nanoparticles in relevant cell types in vitro and in vivo. Some nanoparticles induce oxidative stress in association with lipid droplet formation in different cell types, ${ }^{8-10}$ including microglia. Microglia are considered the principal immune cells of the CNS, and they respond to different pathological agents with a reaction termed microglia activation. ${ }^{11}$ Once activated, microglia release both neuroprotective and cytotoxic molecules, including nitric oxide, reactive oxygen species, toxic prostanoids, ${ }^{12}$ and proinflammatory cytokines, such as tumor necrosis factor- $\alpha$ (TNF- $\alpha$ ) or interleukin-1 $\beta$ (IL-1 $\beta$ ), thereby affecting neuronal functions. ${ }^{13-17}$

(3) Mistry, A.; Glud, S. Z.; Kjems, J.; Randel, J.; Howard, K. A.; Stolnik, S.; Illum, L. Effect of physicochemical properties on intranasal nanoparticle transit into murine olfactory epithelium. J. Drug Targeting 2009, 17 (7), 543-52.

(4) Wang, Z. L.; Cheng, S. M.; Ma, M. M.; Ma, Y. P.; Yang, J. P.; $\mathrm{Xu}$, G. L.; Liu, X. F. Intranasally delivered bFGF enhances neurogenesis in adult rats following cerebral ischemia. Neurosci. Lett. 2008, 446 (1), 30-5.

(5) Yang, J. P.; Liu, H. J.; Cheng, S. M.; Wang, Z. L.; Cheng, X.; Yu, H. X.; Liu, X. F. Direct transport of VEGF from the nasal cavity to brain. Neurosci. Lett. 2009, 449 (2), 108-11.

(6) Lalancette-Hebert, M.; Phaneuf, D.; Soucy, G.; Weng, Y. C.; Kriz, J. Live imaging of Toll-like receptor 2 response in cerebral ischaemia reveals a role of olfactory bulb microglia as modulators of inflammation. Brain 2009, 132 (Part 4), 940-54.

(7) Marks, D. R.; Tucker, K.; Cavallin, M. A.; Mast, T. G.; Fadool, D. A. Awake intranasal insulin delivery modifies protein complexes and alters memory, anxiety, and olfactory behaviors. J. Neurosci. 2009, 29 (20), 6734-51.

(8) Khatchadourian, A.; Maysinger, D. Lipid droplets: their role in nanoparticle-induced oxidative stress. Mol. Pharmaceutics 2009, 6 (4), 1125-37.

(9) Khatchadourian, A.; Krumova, K.; Boridy, S.; Ngo, A. T.; Maysinger, D.; Cosa, G. Molecular imaging of lipid peroxyl radicals in living cells with a BODIPY-alpha-tocopherol adduct. Biochemistry 2009, 48 (24), 5658-68.

(10) Przybytkowski, E.; Behrendt, M.; Dubois, D.; Maysinger, D. Nanoparticles can induce changes in the in tracellular metabolism of lipids without compromising cellular viability. FEBS J. 2009, 276 (21), 6204-17.

(11) Hanisch, U. K.; Kettenmann, H. Microglia: active sensor and versatile effector cells in the normal and pathologic brain. Nat. Neurosci. 2007, 10 (11), 1387-94.

(12) Gibson, C. L.; Coughlan, T. C.; Murphy, S. P. Glial nitric oxide and ischemia. Glia 2005, 50 (4), 417-26.

(13) Dirnagl, U.; Iadecola, C.; Moskowitz, M. A. Pathobiology of ischaemic stroke: an integrated view. Trends Neurosci. 1999, 22 (9), 391-7.

(14) Raivich, G.; Jones, L. L.; Werner, A.; Bluthmann, H.; Doetschmann, T.; Kreutzberg, G. W. Molecular signals for glial activation: pro- and anti-inflammatory cytokines in the injured brain. Acta Neurochir. Suppl. 1999, 73, 21-30.
In the present study, we investigated microglial activation in response to intranasal delivery of nanoparticles. Quantum dots (QD) were selected because they are among the most studied fluorescent nanoparticles for in vivo imaging, ${ }^{18-20}$ but their effects on microglia have not been extensively explored. QDs have excellent photophysical properties, and their surfaces can be relatively easily modified. QDs employed in this study were surface-capped with cysteamine or polyethylene glycol (PEG), or surface-conjugated with lipopolysaccharide (LPS) to form LPS-QD micelles.

Although microglia activation after inhalation of ultrafine nanoparticles (UFPs) in humans has been suggested by Obersdorster, ${ }^{21}$ the involvement of any receptors along the journey from the nose to the lungs or brain has not been clearly demonstrated. Studies in rodents exposed to UFPs via the intranasal route are mainly focused on their effects in the lungs and the heart. ${ }^{22-24}$ The aim of this study was to assess the central (olfactory bulb) microglial response to distinctly different surfaces on $\mathrm{CdSe} / \mathrm{ZnS}$ nanoparticles bearing either cysteamine, PEG or LPS, and to establish markers for screening microglial response triggered by these and other nanoparticles in vitro and in vivo.

We report here that (i) LPS-QD micelles induced significantly enhanced microglial activation both in N9 microglia cells and in Toll-like receptor (TLR)-2 reporter mice, as compared with QDs alone; (ii) enhanced TLR2 expression can be used as a real-time functional biomarker of immune response to intranasally delivered nanoparticles; and (iii) lipid

(15) Allan, S. M.; Rothwell, N. J. Cytokines and acute neurodegeneration. Nat. Rev. Neurosci. 2001, 2 (10), 734-44.

(16) Hanisch, U. K. Microglia as a source and target of cytokines. Glia 2002, 40 (2), 140-55.

(17) Rogove, A. D.; Lu, W.; Tsirka, S. E. Microglial activation and recruitment, but not proliferation, suffice to mediate neurodegeneration. Cell Death Differ. 2002, 9 (8), 801-6.

(18) Giepmans, B. N.; Adams, S. R.; Ellisman, M. H.; Tsien, R. Y. The fluorescent toolbox for assessing protein location and function. Science 2006, 312 (5771), 217-24.

(19) Alivisatos, A. P.; Gu, W.; Larabell, C. Quantum dots as cellular probes. Annu. Rev. Biomed. Eng. 2005, 7, 55-76.

(20) Medintz, I. L.; Mattoussi, H. Quantum dot-based resonance energy transfer and its growing application in biology. Phys. Chem. Chem. Phys. 2009, 11 (1), 17-45.

(21) Oberdorster, G.; Elder, A.; Rinderknecht, A. Nanoparticles and the brain: cause for concern. J. Nanosci. Nanotechnol. 2009, 9 (8), 4996-5007.

(22) Tong, H.; McGee, J. K.; Saxena, R. K.; Kodavanti, U. P.; Devlin, R. B.; Gilmour, M. I. Influence of acid functionalization on the cardiopulmonary toxicity of carbon nanotubes and carbon black particles in mice. Toxicol. Appl. Pharmacol. 2009, 239 (3), 22432.

(23) Totlandsdal, A. I.; Refsnes, M.; Skomedal, T.; Osnes, J. B.; Schwarze, P. E.; Lag, M. Particle-induced cytokine responses in cardiac cell cultures-the effect of particles versus soluble mediators released by particle-exposed lung cells. Toxicol. Sci. 2008, 106 (1), 233-41.

(24) Yu, L. E.; Yung, L. Y.; Ong, C. N.; Tan, Y. L.; Balasubramaniam, K. S.; Hartono, D.; Shui, G.; Wenk, M. R.; Ong, W. Y. Translocation and effects of gold nanoparticles after inhalation exposure in rats. Nanotoxicology 2007, 1 (3), 235-42. 
droplets, commonly considered as lipid storage sites in adipogenic tissues, are formed in activated microglia, suggesting their role in inflammation of the CNS.

\section{Experimental Section}

PEGylated nanoparticles (Qdot 705, Q21591) were purchased from Invitrogen and were used as control nanoparticles in biological in vitro and in vivo experiments. CdSe/ $\mathrm{ZnS}$ nanoparticles with double $\mathrm{ZnS}$ shells and modified cysteamine and LPS surfaces were prepared as described by Betanzos et al. ${ }^{25}$ All chemicals were of the purest quality purchased commercially.

Preparation and Characterization of Nanoparticles. Synthesis of CdSe/ZnSe/ZnS QDs: ${ }^{26}$ The core of cadmium selenide $(\mathrm{CdSe})$ was prepared by heating to $220{ }^{\circ} \mathrm{C}, 51.4$ $\mathrm{mg}(0.4 \mathrm{mmol})$ of cadmium oxide $(\mathrm{CdO})$ and $455 \mathrm{mg}(1.6$ $\mathrm{mmol}$ ) of stearic acid (SA) until the solution turned transparent under $\mathrm{N}_{2}$ with a condenser. After cooling to room temperature (RT), $2 \mathrm{~g}$ of trioctylphosphine oxide (TOPO), $2 \mathrm{~g}$ of octadecylamine (ODA) and $16 \mathrm{~mL}$ of octadecene (ODE) were added. The solution was then heated to 260-270 ${ }^{\circ} \mathrm{C}, 3 \mathrm{~mL}$ of $1.0 \mathrm{M}$ TOPSe (190 mg of selenide and $3 \mathrm{~mL}$ of trioctylphosphine) was quickly injected and the heater was removed very quickly (the size of QDs depends on the reaction temperature and time).

The first shell was grown without separation of the CdSe cores. After cooling the reaction mixture to RT, $10 \mathrm{~mL}$ of $0.2 \mathrm{M}$ zinc undecylenate $\left(1.73 \mathrm{~g}\right.$ of $\left.\mathrm{Zn}(\mathrm{UD})_{2}\right)$ in dioctylamine (DOA) was quickly injected. The temperature was slowly increased to $220^{\circ} \mathrm{C}$ over a time lapse of about an hour, and maintained for $30 \mathrm{~min}$ to grow the $\mathrm{ZnSe}$ shell. Then the heater was removed to cool the solution to RT. The reaction was monitored by diluting samples in chloroform and observing the absorbance and luminescence.

The second shell of $\mathrm{ZnS}$ was grown by quickly injecting into the crude CdSe/ZnSe QD solution at RT, $100 \mathrm{mg}$ (3 $\mathrm{mmol}$ ) of sulfur (S) dissolved in $10 \mathrm{~mL}$ of ODE. The reaction was then heated to $220^{\circ} \mathrm{C}$ and maintained for $1.5 \mathrm{~h}$, before decreasing to $60^{\circ} \mathrm{C}$ for an overnight period. Once again the reaction was monitored by diluting samples in chloroform and observing under UV.

To separate the QDs from the reaction mixture, the reaction solution was first diluted into hexane before being centrifuged at $8,000 \mathrm{rpm}$ for $10 \mathrm{~min}$ to remove the reagents which were insoluble. The red supernatant solution was then isolated and precipitated out from the solution by adding anhydrous methanol followed by centrifugation at 14,000 rpm for $8 \mathrm{~min}$. The precipitate was washed with methanol, and the QDs were then dissolved in chloroform to obtain the stock solution.

(25) Betanzos, C. M.; Gonzalez-Moa, M.; Johnston, S. A.; Svarovsky, S. A. Facile labeling of lipoglycans with quantum dots. Biochem. Biophys. Res. Commun. 2009, 380 (1), 1-4.

(26) Kim, J. I.; Lee, J.-K. Sub-kilogram-Scale One-Pot Synthesis of Highly Luminescent and Monodisperse Core/Shell Quantum Dots by the Successive Injection of Precursors. Adv. Funct. Mater. 2006, 16 (16), 2077-82.
Preparation of LPS-QD Micelles. LPS-QDs were prepared based on the method described by Betanzos et al. ${ }^{25}$ Briefly, the stock solution was first diluted to a concentration of $1 \mu \mathrm{M}$ in chloroform. A $100 \mu \mathrm{L}$ aliquot of the chloroform solution was diluted to $500 \mu \mathrm{L}$ with chloroform and mixed with $100 \mu \mathrm{L}$ of $10 \mathrm{mg} / \mathrm{mL}$ aqueous solution of corresponding lipoglycan (Escherichia coli O111:B4). Methanol was added dropwise with occasional vortexing until complete mixing of the two phases was achieved (about $400 \mu \mathrm{L}$ of methanol).

This homogeneous mixture of 5/4/1 chloroform/methanol/ water was then evaporated to dryness under a flow of nitrogen. The solid residue obtained was resuspended in 100 $\mu \mathrm{L}$ of $\mathrm{ddH}_{2} \mathrm{O}$.

A saturated solution of tetramethylammonium hydroxide pentahydrate $\left(\mathrm{Me}_{4} \mathrm{~N}^{+} \mathrm{OH}^{-} \cdot 5 \mathrm{H}_{2} \mathrm{O}\right)$ was added until $\mathrm{pH} 11$ (ca. $5 \mu \mathrm{L}$ ). The solution was sonicated for $30 \mathrm{~min}$ and then passed through two consecutive Zeba columns ( $2 \mathrm{~mL}$, Pierce) to remove salts and excess of free LPS.

Characterization of QD and LPS-QD Micelles. The UV-vis absorbance was taken on a Hewlett-Packard diode array spectrophotometer, model $8452 \mathrm{~A}$, between the wavelengths of $200-820 \mathrm{~nm}$ with a maximum peak around 580 $\mathrm{nm}$. The fluorescence spectroscopy was observed on a fluorescence reader from Varian Cary Eclipse after an excitation at $365 \mathrm{~nm}$ with a window of emission between 500 and $700 \mathrm{~nm}$. The slits were set at 2.5 and $2.5 \mathrm{~nm}$, with a voltage between 600 and $900 \mathrm{~V}$ depending on the intensity of the luminescence.

The concentration of the QDs in chloroform was determined using the wavelength and the absorbance of the first excitonic peak as described by $\mathrm{Yu}$ et al. ${ }^{3}$

For CdSe QDs:

$$
\begin{aligned}
D(\mathrm{~nm})=\left(1.6122 \times 10^{-9}\right) \lambda^{4}-\left(2.6575 \times 10^{-6}\right) \lambda^{3}+ \\
\left(1.6242 \times 10^{-3}\right) \lambda^{2}-(0.4277) \lambda+(41.57)
\end{aligned}
$$

$\lambda$ is the wavelength of the first excitonic absorption peak of the corresponding sample. The extinction coefficient of the particle is determined for CdSe as $\varepsilon(\mathrm{L} /(\mathrm{cm} \cdot \mathrm{mL}))=5857$ (D) $)^{2.65}$.

TEM sizing of QD core/double shell: To observe of the size distribution of the nanocrystals, one drop of a dilute sample of quantum dots in chloroform or functionalized QDs in water was placed onto a Formvar-coated copper grid or a polymer-coated carbon grid respectively, allowed to settle for 5 min and wicked away using an absorbent pad. The grid was then placed in a FEI Tecnai $12,120 \mathrm{kV}$ with a Gatan 792 Bioscan $1 \mathrm{k} \times 1 \mathrm{k}$ wide angle multiscan CCD camera (Facility for Electron Microscopy Research, Department of Anatomy and Cell Biology, McGill University).

Animal Studies. All of the animal procedures used in the studies were approved by the Animal Research Ethics Board of Laval University, and conformed to the Canadian Council on Animal Care guidelines.

Transgenic TLR2-luc/gfp mice were used to study microglial activation/TLR2 response after intranasal delivery of nanoparticles. In this mouse model, reporter genes luciferase 
(Luc) and green fluorescent protein (gfp) from a bicistronic DNA construct were driven under the transcriptional control of the murine TLR2 promoter. As previously described, ${ }^{6}$ transgenic animals were identified by PCR detection of luciferase and/or Southern blot analyses. TLR2-luc/gfp mice will be kept as a heterozygous ( \pm for the reporter genes). Genomic DNA from ear punches or tail snips was PCRamplified using luciferase specific oligonucleotides K3, $5^{\prime}$ ggcgcagtaggcaaggtggt- $3^{\prime}$, and K4, 5'-cagcaggatgctctccagttc$3^{\prime}$, under standard conditions with the HotStar Taq Mastermix kit (Qiagen, Mississauga, Ontario, Canada). The PCR conditions were $95{ }^{\circ} \mathrm{C}-15 \mathrm{~min}, 30$ cycles $\left(94{ }^{\circ} \mathrm{C}-30 \mathrm{~s}, 65^{\circ} \mathrm{C}-30\right.$ $\mathrm{s}, 72{ }^{\circ} \mathrm{C}-1 \mathrm{~min} 72{ }^{\circ} \mathrm{C}-7 \mathrm{~min}$ ). The expected $300 \mathrm{bp}$ fragments were visualized on agarose gels. ${ }^{6,27}$

Intranasal Administration of Nanoparticles. Mice were anesthetized using $2 \%$ isoflurane in $100 \%$ oxygen at a flow rate of $2 \mathrm{~L} / \mathrm{min}$. Transgenic mice $(n=4)$ received intranasally, into the left nostril, $5 \mu \mathrm{L}$ of nanoparticle suspension. Control mice $(n=4)$ received intranasally $5 \mu \mathrm{L}$ of sterile $0.9 \%$ saline solution. The animals were then longitudinally imaged using in vivo bioluminescence.

In Vivo Optical Small Animal Imaging. Images were gathered using IVIS 200 imaging system (CaliperLSXenogen, Alameda, CA). Twenty-five minutes prior to the imaging session, the mice received intraperitoneal (ip) injection of the luciferase substrate D-luciferine $(150 \mathrm{mg} /$ $\mathrm{kg}$ : for mice between 20 and $25 \mathrm{~g}, 150-187.5 \mu \mathrm{L}$ of a solution of $20 \mathrm{mg} / \mathrm{mL}$ of D-luciferine dissolved in $0.9 \%$ saline was injected) (CaliperLS-Xenogen, Alameda, CA). The mice were then anesthetized with $2 \%$ isoflurane in $100 \%$ oxygen at a flow rate of $2 \mathrm{~L} / \mathrm{min}$ and placed in the heated, lighttight imaging chamber and maintained anesthetized by constant delivery of $2 \%$ isoflurane/oxygen mixture at $1 \mathrm{~L} / \mathrm{min}$ through an IVIS anesthesia manifold. Images were collected using a high sensitivity (CCD) camera with wavelengths ranging from 300 to $660 \mathrm{~nm}$. Exposition time for imaging was $1-2 \mathrm{~min}$. The bioluminescence emission was normalized and displayed in physical units of surface radiance, photons per second per centimeter squared per steradian (photons/s/ $\mathrm{cm}^{2} / \mathrm{sr}$ ). For fluorescence, a $150 \mathrm{~W}$ tungsten-halogen lamp was used with a light guide to a six-position excitation filter wheel. An optimized Cy5.5 filter set was used for acquiring in vivo fluorescence of Qdot 705. ${ }^{28}$ The same imaging protocols were performed immediately after injection of fluorescent nanoparticles and then at different times as indicated in the figure legends. The light output was quantified by determining the total number of photons emitted per second using the Living Image 2.5 acquisition and imaging software (CaliperLS-Xenogen, Alameda, CA). Region of interest (ROI) measurements on the images were used to convert surface radiance (photons $/ \mathrm{s} / \mathrm{cm}^{2} / \mathrm{sr}$ ) to source flux or total flux of photons expressed in photons/second $(\mathrm{p} / \mathrm{s})$. The data were represented as pseudocolor images

(27) Cordeau, P., Jr.; Lalancette-Hebert, M.; Weng, Y. C.; Kriz, J. Live imaging of neuroinflammation reveals sex and estrogen effects on astrocyte response to ischemic injury. Stroke 2008, 39 (3), 93542. indicating light intensity (red and yellow, most intense) which were superimposed over grayscale reference photographs.

Tissue Collection and Immunofluorescence. After intranasal delivery of different nanoparticles, the animals were anesthetized by an ip injection of chloral hydrate $(150 \mathrm{mg} /$ $\mathrm{kg}, 300-350 \mu \mathrm{L}$ of solution, $10 \mathrm{mg} / \mathrm{mL}$ ) and transcardially perfused with $30 \mathrm{~mL}$ of $0.9 \%$ saline, followed by $4 \%$ paraformaldehyde (PFA) at $\mathrm{pH} 7.4$ dissolved in phosphate buffered saline (PBS). Tissue samples were then postfixed overnight in 4\% PFA and equilibrated in PBS $30 \%$ sucrose for $48 \mathrm{~h}$. Brains were embedded into Tissue-Tek (OCT compound, Sakura, USA), frozen at $-20^{\circ} \mathrm{C}$, cut into coronal sections with a cryostat ( $35 \mu \mathrm{m}$ thick) and stored at -20 ${ }^{\circ} \mathrm{C}$. Brain sections were placed in blocking solution (PBS containing $10 \%$ goat serum and $0.25 \%$ Triton X-100) for $30 \mathrm{~min}$. Using the same buffer solution, the sections were then incubated overnight at room temperature using primary antibodies, 1:750 rabbit polyclonal anti-Iba1 (Wako, Richmond, VA), and 1:1500 anti-CD68 (Serotec, Raleigh, NC), 1:1000 anti-Mac2 (ATCC, Manassas, VA). After being washed in PBS, the sections were incubated in corresponding fluorescent goat secondary antiserum (Invitrogen, Burlington, ON, Canada). The sections were then mounted on coverslips with Fluoromount G (Electron Microscopy Sciences, Burlington, ON, Canada) after being washed in PBS $1 \mathrm{X}$ as described previously. ${ }^{28,29}$

Cell Treatment and Measurement of Mitochondrial Metabolic Activity of Microglia Cells. Mouse microglia cells (N9) were seeded in 24-well plates $\left(1 \times 10^{5}\right.$ cells/well) $24 \mathrm{~h}$ prior to treatment. Cells were cultured in IMDM media containing $5 \%$ fetal bovine serum and $1 \%$ penicillinstreptomycin, and maintained at $37{ }^{\circ} \mathrm{C}\left(5 \% \mathrm{CO}_{2}\right)$ in a humidified atmosphere. $\mathrm{N} 9$ cells were treated for $24 \mathrm{~h}$ with cysteamine-capped quantum dots (QD; $5 \mathrm{nM})$, lipopolysaccharide-QD micelles (LPS-QD) and the drug lipopolysaccharide $(10 \mu \mathrm{g} / \mathrm{mL})$ in combination or separately.

Mitochondrial metabolic activity of cells was measured using the colorimetric MTT assay (Sigma). After treatment, medium was removed and replaced with nanoparticle-free, serum-free medium (500 $\mu \mathrm{L} /$ well). MTT solution $(12 \mu \mathrm{M})$ was added to cells and incubated for $40 \mathrm{~min}$ at $37^{\circ} \mathrm{C}$. Cells were then lysed, and formazan was dissolved with dimethyl sulfoxide (DMSO, Sigma). Absorbance was measured at 595 $\mathrm{nm}$ using a Benchmark microplate reader (Bio-Rad, Mississauga, ON, Canada). The extent of formazan conversion is expressed in percentages relative to the untreated control. All measurements were done in triplicate in three or more

(28) Maysinger, D.; Behrendt, M.; Lalancette-Hebert, M.; Kriz, J. Realtime imaging of astrocyte response to quantum dots: in vivo screening model system for biocompatibility of nanoparticles. Nano Lett. 2007, 7 (8), 2513-20.

(29) Lalancette-Hebert, M.; Gowing, G.; Simard, A.; Weng, Y. C.; Kriz, J. Selective ablation of proliferating microglial cells exacerbates ischemic injury in the brain. J. Neurosci. 2007, 27 (10), 2596-605. 
independent experiments. Additional cell viability assays, including cell counting, confirmed the results from the MTT assays.

Nitric Oxide Production by Microglia. Nitric oxide release was measured in N9 microglia using the Griess reagent (Sigma). Briefly, after treatment, $50 \mu \mathrm{L}$ of Griess reagent was added to $50 \mu \mathrm{L}$ of sample (cell supernatant) and incubated at room temperature for $15 \mathrm{~min}$. Absorbance of the converted nitrite from the samples was measured using a spectrophotometer at $540 \mathrm{~nm}$. The results are expressed as mean \pm SEM obtained from at least three independent experiments performed in triplicate.

Immunocytochemistry and Lipid Droplet Staining. Lipid droplets (LD) in microglia were stained with the BODIPY 493/503 dye (Molecular Probes) as described previously. ${ }^{8}$ Briefly, $24 \mathrm{~h}$ before treatment, N9 cells were seeded on glass coverslips coated with rat-tail collagen. After treatment, cells were washed with PBS and fixed with $4 \%$ paraformaldehyde. Cells were then permeabilized using $0.1 \%$ Triton-X 100 at room temperature for $5 \mathrm{~min}$, and blocked with 1\% BSA (in PBS) for $30 \mathrm{~min}$. Cells were first stained with Phalloidin-Alexa594 (Molecular Probes) for $30 \mathrm{~min}$ at room temperature, then stained with BODIPY 493/503 and Hoechst 33342 (Molecular Probes) at room temperature for $10 \mathrm{~min}$. Cells were washed twice with PBS and mounted onto glass slides (Fisher Scientific, \#12-550-15) with Vectashield H-1000 (Vector Laboratories, Burlingame, CA). Images were acquired with a fluorescent microscope (Leica DMI4000B) at $63 \times$. Pictures were captured with the Leica DFC 350 FX camera and analyzed using the Leica Application Suite program. The number and size of lipid droplets per cell per condition were counted and measured manually. The median surface area of the lipid droplets was expressed as $\mu \mathrm{m}^{2}$ per treatment. At least ten fields from four slides were analyzed per condition.

Statistical Analysis. Statistical analysis was performed using Systat (version 10.2). Two sample $t$ test was used when only two groups were being compared. Multiple comparisons were done with one-way ANOVA, followed by Bonferroni's correction post-hoc test. All data are presented as mean \pm SEM. $p<0.05$ was considered significant.

\section{Results}

Quantum Dots Modified with Lipopolysaccharide Form Micellar Nanoparticles. Lipopolysaccharides (LPS) are endotoxins found on the outer membrane of Gramnegative bacteria, and they can elicit robust immune responses when in contact with mammalian cells. ${ }^{30}$ LPS molecules form micelles in aqueous solutions, due to their amphiphilic nature: hydrophilic polysaccharide head groups, bound by glycolipids to lipid A molecules which constitute the micelle core (Figure 1A). Hydrophobic nanoparticles, such as trioctylphosphine oxide (TOPO)-conjugated QDs,

(30) Rivest, S. Molecular insights on the cerebral innate immune system. Brain Behav. Immun. 2003, 17 (1), 13-9. can be easily encapsulated into LPS micelles, forming larger micellar complexes, ranging between 80 and $180 \mathrm{~nm}$ in diameter (Figure 1B,C). The approach used to encapsulate the QDs in LPS micelles is based on the affinity between hydrophobic surfaces and a lipid environment. Some basic properties of the nanoparticles investigated in this study are summarized in Table 1. Nonfunctionalized TOPO-QDs were selected because of the well-documented hydrophobic characteristics of trioctylphosphine oxide. ${ }^{31}$ LPS-modified CdSe/ $\mathrm{ZnSe} / \mathrm{ZnS}$ nanoparticles were visualized and characterized by transmission electron microscopy (TEM), dynamic light scattering (DLS) and spectrophotometry. The actual size and shape were assessed by TEM and DLS (Figure 1B). The absorption spectra were recorded and used for the determination of nanoparticle concentrations. The size distribution data from the EM studies (Figure 1C) show significant differences in sizes between the starting QDs with TOPO on the surface $(6-8 \mathrm{~nm})$, those with PEG $(20-25 \mathrm{~nm})$, and the LPS-QD micelles $(156.6 \pm 13 \mathrm{~nm})$.

Intranasal Administration of LPS-QD Micelles Results in Enhanced Activation of Olfactory Bulb Microglia. Microglia are important modulators of inflammation in the brain, acting as resident macrophages upon detection of foreign objects or hostile environments. ${ }^{32}$ The olfactory bulb (OB) contains a population of highly sensitive microglia that can readily migrate to other brain regions upon stimulus. ${ }^{33}$ To visualize microglial activation/Toll-like receptor (TLR)-2 response following intranasal delivery of nanoparticles in live animals, we used a TLR2 reporter mouse model. ${ }^{6}$ In this animal model, the dual reporter system luciferase/green fluorescent protein is expressed under transcriptional control of a murine TLR2 promoter. A transcriptional activation of TLR2 was visualized in the brains of live animals using biophotonic/ bioluminescence molecular imaging and a high resolution, high sensitivity charged coupled device (CCD) camera. Normally, in the mouse brain, TLR2 expression is very low or undetectable, but it is strongly induced in activated microglial cells in response to infection, noxious stimuli and/or brain injury. Bioluminescence from activated microglia in transgenic Tlr-2-Fluc/gfp mice was assessed from the same animals before and after intranasal nanoparticle administration (Figure 2A). As shown in Figure $2 \mathrm{~A}$, bioluminescence signals corresponding to the olfactory bulb region are detected prior to nanoparticle administration (left panels), suggesting that there are activated

(31) Wang, M.; Zhang, M.; Qian, J.; Zhao, F.; Shen, L.; Scholes, G. D.; Winnik, M. A. Enhancing the photoluminescence of polymerstabilized CdSe/CdS/ZnS core/shell/shell and CdSe/ZnS core/shell quantum dots in water through a chemical-activation approach. Langmuir 2009, 25 (19), 11732-40.

(32) Gonzalez-Scarano, F.; Baltuch, G. Microglia as mediators of inflammatory and degenerative diseases. Annu. Rev. Neurosci. 1999, 22, 219-40.

(33) Ekdahl, C. T.; Kokaia, Z.; Lindvall, O. Brain inflammation and adult neurogenesis: the dual role of microglia. Neuroscience $\mathbf{2 0 0 9}$, 158 (3), 1021-9. 

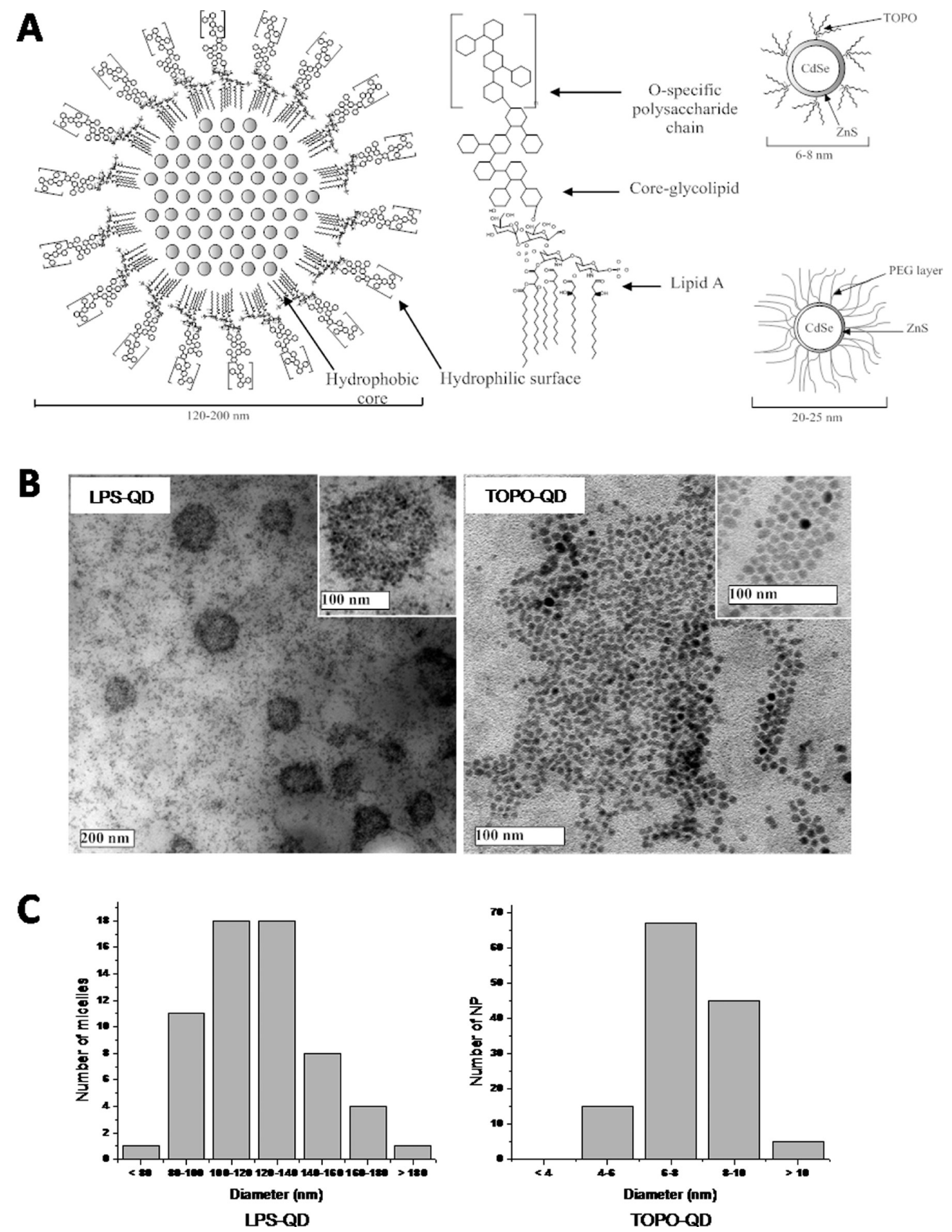

Figure 1. Schematics and characterization by TEM of QD-LPS structures and their components. (A) Representation of LPS-QD structures where hydrophobic CdSe/ZnSe/ZnS quantum dots are encapsulated in the hydrophobic core of LPS micelles; generic structure of lipopolysaccharide (LPS); schematic of hydrophobic CdSe/ZnSe/ZnS quantum dots coated with trioctylphosphine oxide; schematic of CdSe/ZnS quantum dots encapsulated in a hydrophilic PEG layer. (B) (left) TEM image of hydrophobic CdSe/ZnSe/ZnS quantum dots coated with TOPO deposited on a carbon coated grid. (right) TEM image of nonpurified LPS-QD conjugates in water, showing the incorporation of hydrophobic QDs in LPS micelles, deposited on a Formvar-coated grid. The instrument used was a FEI Tecnai 12, $120 \mathrm{kV} \mathrm{TEM}$. (C) Size distribution of LPS-QD micelles and TOPO-QDs. Note markedly different sizes ranging from $1-240 \mathrm{~nm}$. Transmission electron microscopy was done in two independent experiments, and the mean values are means of at least 2000-3000 particles analyzed per condition. The mean sizes are expressed as means \pm SEM.

microglia under basal conditions; however LPS and LPSQD micelles significantly increase the TLR2-bioluminescent signals after intranasal delivery. The intensity of the signals in the OB area was markedly stronger following treatment with LPS-QD micelles when compared with controls, i.e. equivalent amounts of QD alone (top panels) or LPS alone. Quantification of the bioluminescence signals from the OB in mice treated with LPS and LPSQDs after $6 \mathrm{~h}$ did not show significant differences in TLR2 expression. In contrast, after $24 \mathrm{~h}$, there was more than 
Table 1. Properties of Nanoparticles with Different Surfaces

\begin{tabular}{lllll}
\hline & \multicolumn{1}{c}{ QD-TOPO } & \multicolumn{1}{c}{ PEG-QD } & \multicolumn{1}{c}{ LPS } & \multicolumn{1}{c}{ LPD micelles } \\
\hline size & $D_{\mathrm{h}}: 5-10 \mathrm{~nm}$ & $D_{\mathrm{h}}: 30-40 \mathrm{~nm}$ & $D_{\mathrm{h}}: 100 \mathrm{~nm}$ & spherical \\
shape & spherical & spherical & negatively charged surface & negheroid \\
charge & no charge: long alkyl chains & no charge & $14.3 \pm 13.3 \mathrm{~nm}$ \\
vol of NP or micelle & $65-525 \mathrm{~nm}^{3}$ & $14,000-33,500 \mathrm{~nm}^{3}$ & $525,000 \mathrm{~nm}^{3}$ & $250,000 \mathrm{~nm}^{3}$ \\
surf area of NP & $78-315 \mathrm{~nm}^{2}$ & $2800-5000 \mathrm{~nm}^{2}$ & $31,500 \mathrm{~nm}^{2}$ & $19,250 \mathrm{~nm}^{2}$ \\
excitation range & $200-550 \mathrm{~nm} ; \max 300 \mathrm{~nm}$ & $405-665 \mathrm{~nm}$ & $\mathrm{n} / \mathrm{a}$ & $200-550 \mathrm{~nm} ; \mathrm{max} 300 \mathrm{~nm}$ \\
emission maxima & $605 \mathrm{~nm}$ & $705 \mathrm{~nm}$ & $\mathrm{n} / \mathrm{a}$ & $605 \mathrm{~nm}$ \\
\hline
\end{tabular}

3 -fold increase in the total photon emission in LPS-QD treated animals $\left(5.4 \pm 0.9\right.$ photons $\left.\times 10^{5} / \mathrm{s}, p<0.01\right)$, which was significantly different when compared to saline $\left(1.2 \pm 0.04\right.$ photons $\left.\times 10^{5} / \mathrm{s}\right)$, PEG-QDs $(1.4 \pm 0.5$ photons $\left.\times 10^{5} / \mathrm{s}\right)$, QDs $\left(2.7 \pm 0.5\right.$ photons $\left.\times 10^{5} / \mathrm{s}\right)$, or LPS $\left(1.5 \pm 0.2\right.$ photons $\left.\times 10^{5} / \mathrm{s}\right)$ alone (Figure $\left.2 \mathrm{~B}\right)$. Additionally, we show that LPS-QD micelles induce TLR2 expression in parietal brain regions also more markedly than QDs without LPS on the surface (Figure 2C, right panels).
A
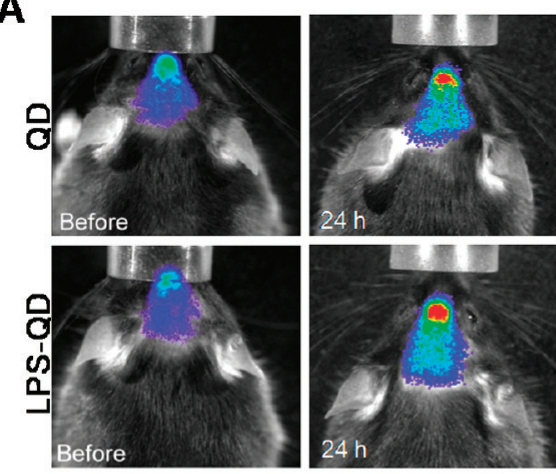

D
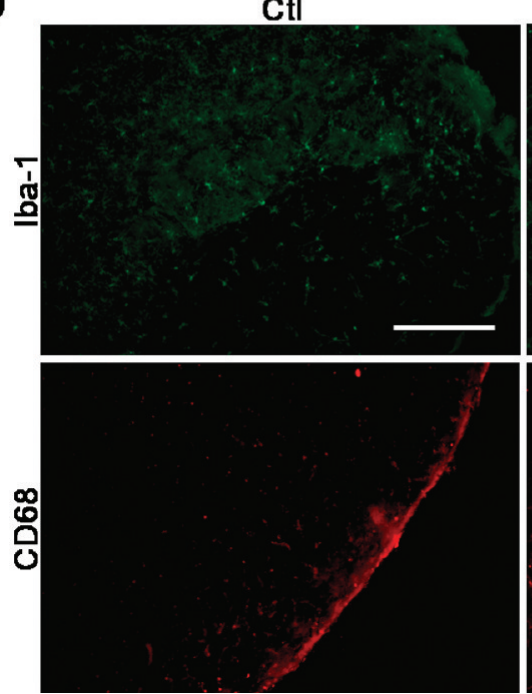

B

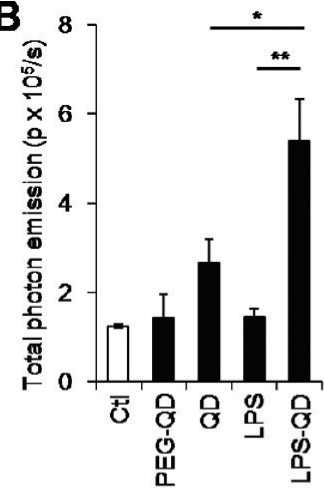

QD

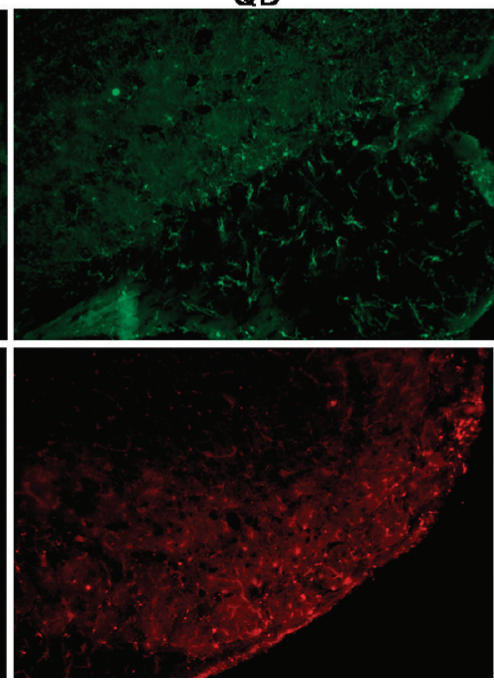

C
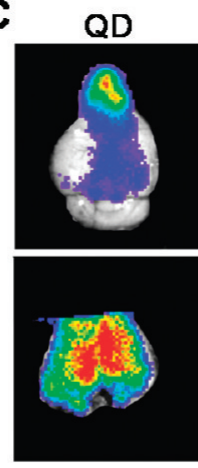

LPS-QD

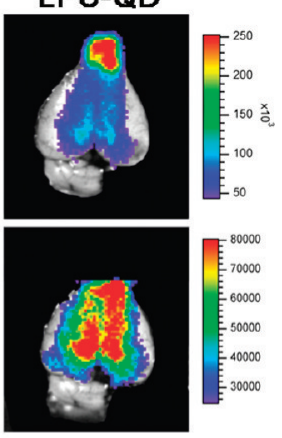

LPS-QD

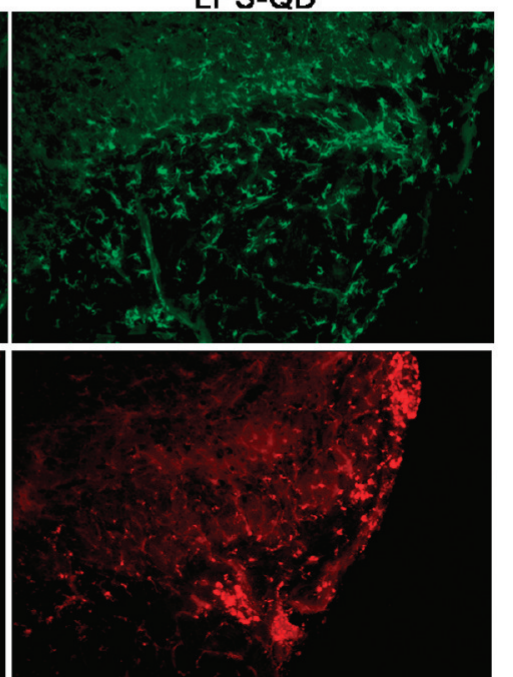

Figure 2. Real-time imaging of TLR2 response following intranasal administration of nanoparticles. (A) QDs (with cysteamine coating) and LPS-QD micelles reveal a marked induction of inflammatory signals in the olfactory bulb area of TLR2 reporter mice in vivo. Photographs of the live TLR2 mice were taken before and 24 after intranasal administration of nanoparticles. The color calibrations at the right are photon counts. (B) Quantification of luciferase activity by the count of total photon emission $(\mathrm{p} / \mathrm{s})$ in the olfactory bulb region. Statistical analysis showed significant increase in TLR2 response (measure of microglial activation) following intranasal administration of LPS-QDs. Values indicate mean \pm SEM (one-way analysis of variance, ${ }^{*} p<0.05,{ }^{* *} p<0.01, n=4-9$ ). (C) Marked luciferase signal was measured ex vivo in the olfactory bulb (top) and other brain regions after intranasal administration of QDs and LPS-QD micelles in TLR2 reporter mice. The color calibrations at the right are photon counts. Note the occurrence of different scales in various ranges. (D) Activated microglial cells from olfactory bulb sections were immunolabeled for lba-1 (green; top row) and CD68 (red), a marker of phagocyting microglial cells (bottom row). Scale bar represents $250 \mu \mathrm{m}$. 
In order to verify whether in vivo imaging response correlated with brain tissue response, following completion of in vivo imaging, animals were perfused and brain sections prepared for immunohistochemistry. Basal microgliosis in the olfactory bulb was detected in untreated animals by immunostaining with the microglia/macrophage marker, ionized calcium-binding adaptor molecule-1 (Iba-1) (Figure 2D, top left). Marked increase in Iba-1 signal was observed in sections from LPS-QD micelle treated animals (top right), suggesting significant induction of microglia activation by these nanoparticles. In contrast, the expression of a known functional marker of microglial activation, cluster of differentiation 68 (CD68), was absent in control, untreated animals (Figure 2D, bottom left), but it was markedly increased after intranasal delivery of QDs (bottom middle). The most significant increase in CD68 expression was observed in sections from LPS-QD micelle treated mice (bottom right). The results obtained using immunohistochemistry are in concordance with our in vivo imaging results suggesting that LPS-QDs induce significant activation of microglia in $\mathrm{OB}$, which may alter the mode of nanoparticle internalization (e.g., receptor-mediated endocytosis, phagocytosis), as well as their biodistribution, and ultimately their therapeutic potential.

Nontoxic, Low Dose LPS-QDs Induce the Formation of Lipid Droplets in Activated Microglia. In the initial experiments using primary neural cultures from olfactory bulb, the exposure to LPS (100 $\mathrm{ng} / \mathrm{mL}$ to $10 \mu \mathrm{g} / \mathrm{mL}$ ), QDs $(1-5 \mathrm{nM})$ or LPS and QDs in combination for $24 \mathrm{~h}$ led to the formation of lipid droplets (LD). Glial fibrillary acidic protein (GFAP)-positive astroglia with large nuclei, representing more than $75 \%$ of the cell population, had only a few lipid droplets. In contrast, many more LDs were found in the less represented (about 10\%) microglia (Figure 3A). To better characterize the response of microglia toward LPS and LPS-QD micelles, we used murine microglia N9 cells to have a more uniform cell population which faithfully responded to pro-inflammatory and trophic stimuli similar to primary microglia. We observed that N9 cells treated with LPS $(10 \mu \mathrm{g} / \mathrm{mL})$ or a low, nontoxic dose of QD $(5 \mathrm{nM}) \mathrm{did}$ not show significant differences in the number or the size of lipid bodies (or lipid droplets) when compared with untreated cells (Figure 3B). Notably, cells treated with LPS-QD micelles had significantly fewer $(4.9 \pm 0.1$ droplets/cell, $p$ $<0.001)$ but larger sized $\left(0.39 \pm 0.02 \mu \mathrm{m}^{2}, p<0.005\right)$ lipid droplets than untreated or LPS- or QD-treated cells (Figure $3 \mathrm{C}, \mathrm{D})$. These opposing changes suggest an altered intracellular distribution of neutral lipids and cholesterol esters, rather than reduced lipid synthesis or enhanced lipid metabolism in response to LPS-QD micelles.

Microglia cells treated with a low, nontoxic dose of QDs or LPS-QD micelles retained mitochondrial metabolic activity and viability after $24 \mathrm{~h}$ (Figure 3E). This low dose of QDs $(5 \mathrm{nM})$ did not induce activation of microglia (measured by the release of nitric oxide, $1.9 \pm 0.1 \mu \mathrm{M}$, and morpho- logical changes), whereas the same concentration of LPSQDs $(5 \mathrm{nM})$ induced significant release of nitric oxide (Figure $3 \mathrm{~F}, 25.8 \pm 0.8 \mu \mathrm{M}, p<0.001)$.

\section{Discussion}

We report here that LPS-QD micelles significantly enhanced microglial activation in vitro and in vivo, as compared with LPS or QDs without LPS on the surface. The novelties of this study are (i) the evidence for toll-like receptor 2 and CD68 upregulation in microglia activated by nanoparticles with LPS, but not with PEG or amine metabolites on the QD surface, (ii) the finding that lipid droplets in microglia can act as early and robust markers for inflammatory/immune response initiation, and (iii) the establishment of the MAPK pathway as a mechanistic link between nanoparticle-induced TLR2 expression and lipid droplet formation in microglia (Figure 4).

Using biophotonic/bioluminescence imaging and the TLR2reporter mouse model, we demonstrate that nanoparticles can trigger $\mathrm{OB}$ microglial activation and the brain's innate immune response via enhanced TLR2, CD68 and iNOS expressions, as well as redistribution of neutral lipids, forming lipid droplets. Our results suggest that the in vivo response of $\mathrm{OB}$ microglial cells can be used as a real-time functional biomarker of immune response to intranasally delivered nanoparticles. The data also revealed that the TLR2-luc/gfp mice represent a suitable model for quantitative assessment of microglial response to nanomaterials and nanoparticles, thereby serving as a widely applicable and easy to use screening system.

Several recent studies show that bionanoparticles and artificial nanoparticles can enter brain tissue. ${ }^{34-40}$ However

(34) Liu, C. H.; You, Z.; Ren, J.; Kim, Y. R.; Eikermann-Haerter, K.; Liu, P. K.; Noninvasive delivery of gene targeting probes to live brains for transcription MRI, FASEB J. 2008, 22 (4), 1193-203.

(35) Potter, W.; Kalil, R. E.; Kao, W. J. Biomimetic material systems for neural progenitor cell-based therapy. Front. Biosci. 2008, 13, 806-21.

(36) Au, C.; Mutkus, L.; Dobson, A.; Riffle, J.; Lalli, J.; Aschner, M. Effects of nanoparticles on the adhesion and cell viability on astrocytes. Biol. Trace Elem. Res. 2007, 120 (1-3), 248-56.

(37) Tsutsui, Y.; Tomizawa, K.; Nagita, M.; Michiue, H.; Nishiki, T.; Ohmori, I.; Seno, M.; Matsui, H. Development of bionanocapsules targeting brain tumors. J. Controlled Release 2007, 122 (2), 15964.

(38) Park, I. K.; Lasiene, J.; Chou, S. H.; Horner, P. J.; Pun, S. H. Neuron-specific delivery of nucleic acids mediated by Tet1modified poly(ethylenimine). J. Gene Med. 2007, 9 (8), 691-702.

(39) Ribot, E.; Bouzier-Sore, A. K.; Bouchaud, V.; Miraux, S.; Delville, M. H.; Franconi, J. M.; Voisin, P. Microglia used as vehicles for both inducible thymidine kinase gene therapy and MRI contrast agents for glioma therapy. Cancer Gene Ther. 2007, 14 (8), 72437.

(40) Voisin, P.; Ribot, E. J.; Miraux, S.; Bouzier-Sore, A. K.; Lahitte, J. F.; Bouchaud, V.; Mornet, S.; Thiaudiere, E.; Franconi, J. M.; Raison, L.; Labrugere, C.; Delville, M. H. Use of lanthanidegrafted inorganic nanoparticles as effective contrast agents for cellular uptake imaging. Bioconjugate Chem. 2007, 18 (4), 105363. 
A
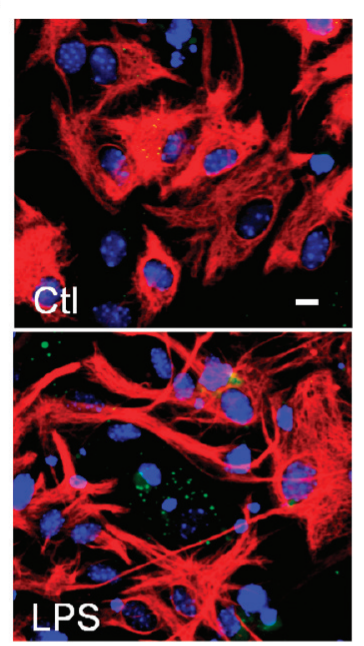

B
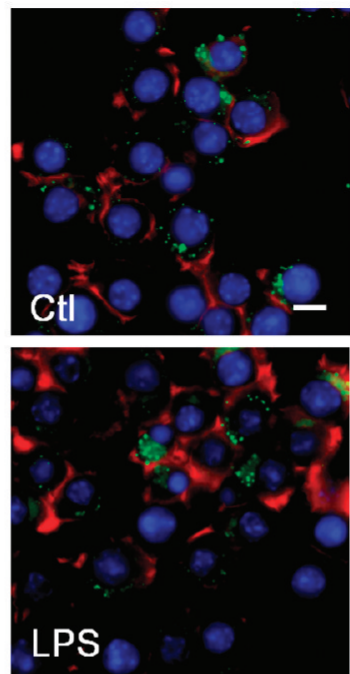
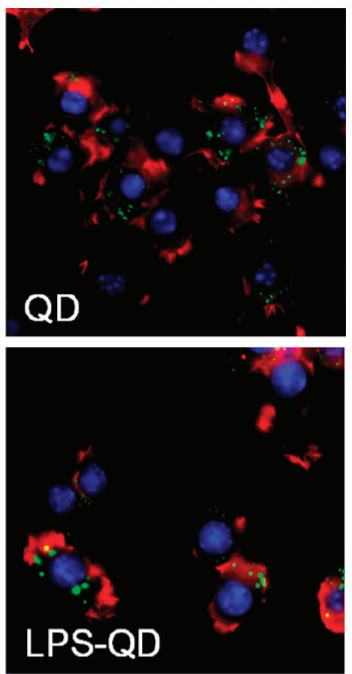
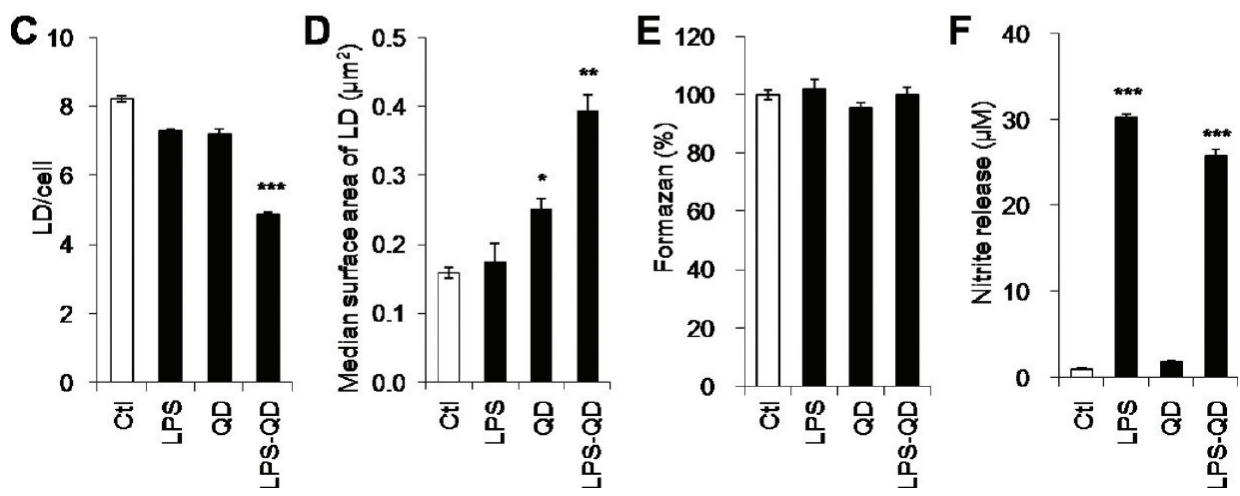

Figure 3. Microglial response to nanoparticles in cell cultures. (A) Murine primary mixed neural cultures from the olfactory bulb treated with LPS showed enhanced expression of lipid droplets in non-astrocytic glia. Lipid droplets are stained with BODIPY (green), nuclei (blue) are stained with Hoechst 33342, and astroglia (red) are immunostained using an antibody against glial fibrillary acidic protein. Scale bar indicates $10 \mu \mathrm{m}$. (B) Fluorescent micrographs of murine microglia (N9 cells) treated with LPS, QDs or LPS-QDs for $24 \mathrm{~h}$ showed differences in the distribution of intracellular lipids. Cytoskeleton (actin) is stained using the phalloidin-Alexa 594 dye (red), and lipid droplets are stained using the BODIPY dye (green). Cell nuclei are stained with Hoechst 33342 . Scale bar represents $10 \mu \mathrm{m}$. Lipid droplets are quantified and expressed as the mean number of lipid droplets per cell (C), and as the median surface area $\left(\mu \mathrm{m}^{2}\right)$ of lipid droplets per condition (D). (E) Mitochondrial metabolic activity as a measure of cell viability of N9 cells treated with LPS, QD or LPS-QD for $24 \mathrm{~h}$. The extent of formazan conversion is expressed in percentages relative to the untreated control. Percent formazan is measured as an assessment of mitochondrial metabolic activity using the MTT assay. ( ${ }^{* *} p<0.001, n=9$.) (F) Relative release of nitrite is measured from N9 cells after $24 \mathrm{~h}$ of treatment (LPS, QD, LPS-QD) in the presence of serum as described previously. Mean values and standard deviations are calculated based on triplicate measurements from at least three independent experiments. Values indicate mean $\pm \operatorname{SEM}\left({ }^{*} p<0.01,{ }^{* *} p<0.005,{ }^{* * *} p<0.001\right)$.

at present, little is known about the differential responses to intranasal nanoparticles, effect of their morphological properties, surface charge, ligand characteristics or size. In addition, there are no reported animal models to assess the response of microglial cells and neurons after intranasal administration in real time. Therefore our present study proposes such a screening system which can be used for different nanoparticles. We selected here cysteamine-capped QDs and those conjugated with LPS on the surface. The olfactory neurons projecting through the mucosa in the upper regions of the nasal cavity are involved in the transport of intranasally administered nanoparticles. A considerable number of studies were performed to explore olfactory toxicity and CNS exposure to metals such as cadmium, cobalt, zinc, nickel, mercury and manganese. ${ }^{41-43}$ Shin et al. showed that $\mathrm{TiO}_{2}$ nanoparticles can enhance LPS-induced neuroinflammation

(41) Villalobos, V.; Bonilla, E.; Castellano, A.; Novo, E.; Caspersen, R.; Giraldoth, D.; Medina-Leendertz, S. Ultrastructural changes of the olfactory bulb in manganese-treated mice. Biocell 2009, 33 (3), 187-97.

(42) Chuang, K. H.; Belluscio, L.; Koretsky, A. P.; In vivo detection of individual glomeruli in the rodent olfactory bulb using manganese enhanced MRI, Neuroimage 2010, 49 (2), 1350-6.

(43) Bondier, J. R.; Michel, G.; Propper, A.; Badot, P. M. Harmful effects of cadmium on olfactory system in mice. Inhalation Toxicol. 2008, 20 (13), 1169-77. 


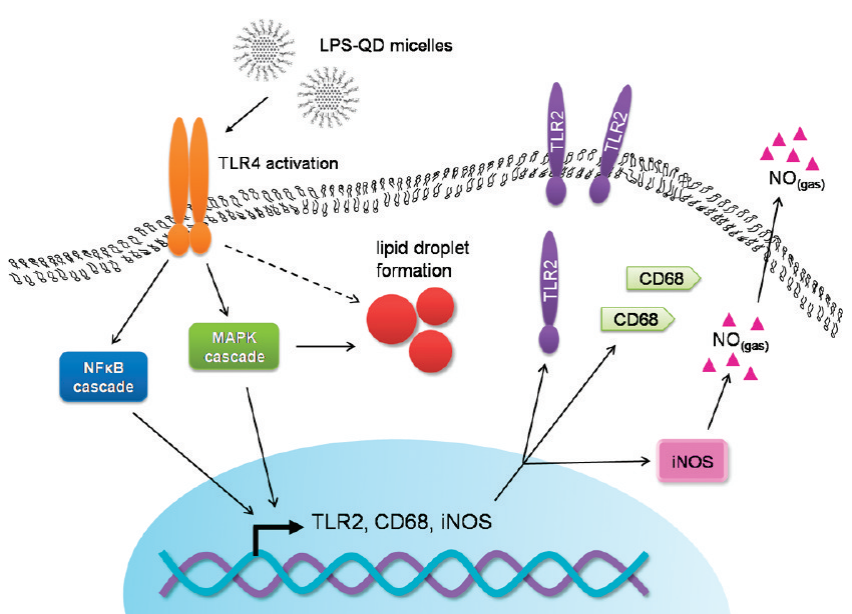

Figure 4. Summary of observed intracellular events following the activation of microglia by LPS-QD micelles. LPS-QD micelles enhance the expressions of TLR2 and CD68, promote the release of nitric oxide and induce the formation of large lipid droplets as hallmarks of microglial activation. Activation of cell surface TLR4 receptors by LPS-QD leads to the (i) activation of the NF- $\kappa \mathrm{B}$ cascade, resulting in the enhanced expression of TLR2; (ii) activation of the MAPK cascade and subsequent transcription of CD68 and inducible nitric oxide synthase (iNOS) measured by the enhanced nitric oxide release; (iii) formation of large lipid droplets.

in vivo, ${ }^{44}$ suggesting that exposure to nanoparticles can potentiate the damage induced during chronic inflammation. $\mathrm{Li}$ et al. reported that gold nanoparticles, administered as an aerosol, can accumulate in the olfactory bulb and in the lungs within 5 days. ${ }^{24}$ In addition, vaccine nanodelivery systems made of polymers such as polylactic, polyglycolic acid, their copolymers or chitosan ${ }^{45}$ were also investigated and physical properties such as surface, charge and size were related to their uptake upon vaccine administration to the nasal cavity. ${ }^{46}$ While these studies provided useful information on nanoparticle distribution and effects in post mortem tissues, the methods used in these studies are limited (e.g., immunohistochemistry, ICP-MS) and cannot provide measurements of cellular response to nanoparticles in a noninvasive manner in real time. Transgenic mouse models such as the one used in this and in previous studies can overcome these limitations, and allow for measurements of cell-specific responses to

(44) Shin, J. A.; Lee, E. J.; Seo, S. M.; Kim, H. S.; Kang, J. L.; Park, E. M. Nanosized titanium dioxide enhanced inflammatory responses in the septic brain of mouse. Neuroscience 2010, 165 (2), 445-54.

(45) Al-Ghananeem, A. M.; Saeed, H.; Florence, R.; Yokel, R. A.; Malkawi, A. H. Intranasal drug delivery of didanosine-loaded chitosan nanoparticles for brain targeting; an attractive route against infections caused by AIDS viruses. J. Drug Targeting 2010, 18 (5), 381-8.

(46) Mistry, A.; Glud, S. Z.; Kjems, J.; Randel, J.; Howard, K. A.; Stolnik, S.; Illum, L. Effect of physicochemical properties on intranasal nanoparticle transit into murine olfactory epithelium. J. Drug Targeting 2009, 17 (7), 543-52. nanomaterials, toxins and therapeutics of neurons, astroglia ${ }^{28}$ and microglia ${ }^{47}$ noninvasively.

Microglia constitute a critically important "surveillance cell network" in the nervous system, and they respond to nanoparticles even if they are in minute quantities, barely or not detectable by common biochemical or biophysical means. The population of microglia located within the olfactory system has higher basal activity (Figure 2) in order to immediately sense the threat by inhaled particles. Results from the present study suggest that microglia are highly responsive to nanoparticles, and their activation lasts for a prolonged time even after a single exposure. A single administration of LPS or LPS-QDs did not produce significant enhancement of TLR2 upregulation after $6 \mathrm{~h}$, but microglial activation reached a maximum after $24 \mathrm{~h}$. A sustained microglial activation after $24 \mathrm{~h}$ was also reported in a study with $\mathrm{TiO}_{2}$ nanoparticles. ${ }^{44}$

Why do we think that, in the context of intranasal drug delivery, the analysis of glial, and in particular microglial, responsiveness should be considered? For example, microglial activation is associated with the release of many proinflammatory cytokines and mediators, some of them potentially neurotoxic. ${ }^{16,48}$ Activation of microglia in response to inflammatory or immune stimuli is associated with the significant induction of several Toll-like receptors (TLRs), ${ }^{49-52}$ normally silent in the brain. While it has been widely established that TLRs are key mediators in the response to invading pathogens and the recognition of pathogen-associated molecular patterns (PAMPs), ${ }^{53-55}$ recent evidence suggests that TLRs, in particular TLR2, have a role in brain response to damage-associated molecular patterns (DAMPS)

(47) Hutter, E.; Boridy, S.; Labrecque, S.; Lalancette-Hebert, M.; Kriz, J.; Winnik, F. M.; Maysinger, D. Microglial Response to Gold Nanoparticles. ACS Nano 2010, DOI 10.1021/nn901869f.

(48) Ransohoff, R. M.; Perry, V. H. Microglial physiology: unique stimuli, specialized responses. Annu. Rev. Immunol. 2009, 27, 119-45.

(49) Olson, J. K.; Miller, S. D. Microglia initiate central nervous system innate and adaptive immune responses through multiple TLRs. J. Immunol. 2004, 173 (6), 3916-24.

(50) Lehnardt, S.; Lehmann, S.; Kaul, D.; Tschimmel, K.; Hoffmann, O.; Cho, S.; Krueger, C.; Nitsch, R.; Meisel, A.; Weber, J. R. Toll-like receptor 2 mediates CNS injury in focal cerebral ischemia. J. Neuroimmunol. 2007, 190 (1-2), 28-33.

(51) Trinchieri, G.; Sher, A. Cooperation of Toll-like receptor signals in innate immune defence. Nat. Rev. Immunol. 2007, 7 (3), 17990.

(52) Ziegler, G.; Harhausen, D.; Schepers, C.; Hoffmann, O.; Rohr, C.; Prinz, V.; Konig, J.; Lehrach, H.; Nietfeld, W.; Trendelenburg, G. TLR2 has a detrimental role in mouse transient focal cerebral ischemia. Biochem. Biophys. Res. Commun. 2007, 359 (3), 574-9.

(53) Schwandner, R.; Dziarski, R.; Wesche, H.; Rothe, M.; Kirschning, C. J. Peptidoglycan- and lipoteichoic acid-induced cell activation is mediated by toll-like receptor 2. J. Biol. Chem. 1999, 274 (25), 17406-9.

(54) Underhill, D. M.; Ozinsky, A.; Hajjar, A. M.; Stevens, A.; Wilson, C. B.; Bassetti, M.; Aderem, A. The Toll-like receptor 2 is recruited to macrophage phagosomes and discriminates between pathogens. Nature 1999, 401 (6755), 811-5. 
and may be implicated in development of brain damage after cerebral ischemia or other types of injuries. In addition, growing evidence suggests potential implication of TLR2 in neurological disorders such as amyotrophic lateral sclerosis (ALS) or Alzheimer's disease. ${ }^{56-58}$ Stimulation of TLR2 signaling pathway in activated microglial cells will lead to transcriptional activation of NF- $\kappa \mathrm{B}$ and consequent production of pro-inflammatory cytokines. In addition, activation of the TLR4 signaling cascade by LPS can also, in turn, activate NF- $\kappa \mathrm{B}$ and subsequently induce the transcription of TLR2 genes. ${ }^{30}$ In keeping with its biological role, induction of TLR2 is considered a good cellular marker of microglial activation ${ }^{59,60}$ Using a TLR2-luc/gfp mouse model and realtime biophotonic/bioluminescence imaging, we recently demonstrated that, once activated, microglia may stay activated for several months after the initial stimulus (ischemic injury). Interestingly, our results revealed some marked microregional distinctions in the microglial phenotypes, i.e. OB microglia are activated even in the absence of a noxious stimulus, and may transduce and modulate immune response to the rest of the brain. This is of particular importance when considering intranasal delivery of nanoparticles and other molecules into the brain, because acute activation of $\mathrm{OB}$ microglia can be translated or propagated to more distal parts. At present, it is not yet clear how this propagation of immune signal may affect the brain's response to different therapies. One of the possibilities is that activated microglia could phagocytose more efficiently or become primed for a second wave of stimuli.

Enhanced CD68 expression following TLR4 stimulation by LPS has been found to be linked with the activation of mitogen-activated protein kinase (MAPK). ${ }^{61}$ Results from this study provide evidence for an increase in CD68 staining

(55) Yoshimura, A.; Lien, E.; Ingalls, R. R.; Tuomanen, E.; Dziarski, R.; Golenbock, D. Cutting edge: recognition of Gram-positive bacterial cell wall components by the innate immune system occurs via Toll-like receptor 2. J. Immunol. 1999, 163 (1), 1-5.

(56) Letiembre, M.; Liu, Y.; Walter, S.; Hao, W.; Pfander, T.; Wrede, A.; Schulz-Schaeffer, W.; Fassbender, K. Screening of innate immune receptors in neurodegenerative diseases: a similar pattern. Neurobiol. Aging 2009, 30 (5), 759-68.

(57) Liu, Y.; Hao, W.; Dawson, A.; Liu, S.; Fassbender, K. Expression of amyotrophic lateral sclerosis-linked SOD1 mutant increases the neurotoxic potential of microglia via TLR2. J. Biol. Chem. 2009, 284 (6), 3691-9.

(58) Zhao, W.; Beers, D. R.; Henkel, J. S.; Zhang, W.; Urushitani, M.; Julien, J. P.; Appel, S. H. Extracellular mutant SOD1 induces microglial-mediated motoneuron injury. Glia 2010, 58 (2), 23143.

(59) Laflamme, N.; Soucy, G.; Rivest, S. Circulating cell wall components derived from Gram-negative, not Gram-positive, bacteria cause a profound induction of the gene-encoding Tolllike receptor 2 in the CNS. J. Neurochem. 2001, 79 (3), 648-57.

(60) Nguyen, M. D.; Julien, J. P.; Rivest, S. Innate immunity: the missing link in neuroprotection and neurodegeneration. Nat. Rev. Neurosci. 2002, 3 (3), 216-27.

(61) Taylor, D. L.; Pirianov, G.; Holland, S.; McGinnity, C. J.; Norman, A. L.; Reali, C.; Diemel, L. T.; Gveric, D.; Yeung, D.; Mehmet, H. Attenuation of proliferation in oligodendrocyte precursor cells by activated microglia. J. Neurosci. Res. 2010, 88 (8), 1632-44. in OB microglia following LPS-QD micelles. Activation of MAPK can induce the expression of inducible nitric oxide synthase (iNOS), thereby increasing the production of nitric oxide (NO), an indicator of activated or inflammatory microglia. Indeed our data shows a significant increase in NO release from microglia treated with LPS-QD micelles.

It was previously shown that MAPK pathways are activated in inflammation, and are involved in the formation of lipid droplets (LDs) in different cell types. ${ }^{62,63}$ LDs have been recently proposed as inflammatory organelles in peripheral macrophages. ${ }^{64}$ Our results from the present study show an inverse relationship between lipid droplet number and their surface areas in microglia treated with LPS-QDs, suggesting a redistribution of neutral lipids in central macrophages rather than de novo synthesis as previously found in PC12 cells under oxidative stress induced by nanoparticles. ${ }^{10}$ Significant changes in LD number and size in activated microglia suggest that LDs can be considered as sensitive indicators of inflammation in the central nervous system (CNS). These changes are associated with an increased cytokine release and likely with reduced lipid utilization. ${ }^{10}$ LDs have been mainly regarded as lipid storage sites under normal physiological conditions, largely involved in maintaining energy balance at the cellular and the whole organism level. ${ }^{65}$ While examining the possible deleterious effects of QDs on different intracellular organelles, we discovered that LDs are intimately involved in the cellular response to QD-induced oxidative stress. ${ }^{8,10}$ The functional significance of LDs in pathological conditions that favor LD generation, e.g. states of excessive fat and cholesterol availability, aging, diabetes, etc., is currently being investigated by different groups including our team.

In summary, the results presented here show marked microglia activation in the olfactory bulb and distal brain region after intranasal administration of LPS-modified QDs. The intensity of bioluminescent signal caused by LPS alone was several fold weaker than that of LPS-QDs, suggesting a potentiation of microglial activation by the two components combined. These results, together with studies by others, investigating intranasal delivery systems, strongly suggest that metallic nanoparticles should not be considered as simple carriers and inert entities but rather as mediators of biological responses in microglia cells (in vitro) and in the whole

(62) Pacheco, P.; Vieira-de-Abreu, A.; Gomes, R. N.; Barbosa-Lima, G.; Wermelinger, L. B.; Maya-Monteiro, C. M.; Silva, A. R.; Bozza, M. T.; Castro-Faria-Neto, H. C.; Bandeira-Melo, C.; Bozza, P. T. Monocyte chemoattractant protein-1/CC chemokine ligand 2 controls microtubule-driven biogenesis and leukotriene B4synthesizing function of macrophage lipid bodies elicited by innate immune response. J. Immunol. 2007, 179 (12), 8500-8.

(63) Murphy, S.; Martin, S.; Parton, R. G. Lipid droplet-organelle interactions; sharing the fats. Biochim. Biophys. Acta 2009, 1791 (6), 441-7.

(64) Bozza, P. T.; Magalhaes, K. G.; Weller, P. F. Leukocyte lipid bodies - Biogenesis and functions in inflammation. Biochim. Biophys. Acta 2009, 1791 (6), 540-51.

(65) Martin, S.; Parton, R. G. Lipid droplets: a unified view of a dynamic organelle. Nat. Rev. Mol. Cell Biol. 2006, 7 (5), 373-8. 
animals (and possibly humans). In addition, the TLR2 reporter mouse model represents a unique and valid model for longitudinal analysis of microglial responsiveness from the brains of live animals. The animal model proposed here complements more invasive approaches (e.g., electron microscopy of tissue sections) which can provide subcellular distribution of nanoparticles, but are of a limited use for monitoring the responsiveness and activation states of microglia in real time. Finally, lipid droplets are organelles responding to the nanoparticles (particularly those deliberately or accidentally associated with LPS), and these changes are reflected both in their total number per cell and in their surface areas. Taken together, altered surface properties of lipid droplets, in different cell types under inflammatory conditions, in combination with surface properties of nanoparticles, could alter nanoparticles subcellular distribution.
Since abnormalities in lipid uptake, lipid redistribution and lipid synthesis could be causally related to different metabolic and neurological disorders, nanoparticles containing therapeutics and designed to interact with these organelles could be of therapeutic value in these disorders.

Acknowledgment. The authors thank Dr. F. Winnik for discussions and the access to the instruments needed to characterize the nanoparticles. This work was supported in part by Canadian Institutes of Health Research and Natural Sciences and Engineering Research Council of Canada. A.O.C. is supported by a doctoral bursary from the Fonds de la Recherche en Santé du Quebec (FRSQ). JK is a recipient of the Career Award from the $R \& D$ Health Research Foundation and CIHR.

MP1000372 